\title{
A Novel Mutation of the Plakophilin-2 Gene in a Child with Early Onset Arrhythmogenic Right Ventricular Cardiomyopathy and Intractable Arrhythmia
}

\author{
Stasa Krasic ${ }^{1}$. Vladislav Vukomanovic ${ }^{1,2} \cdot$ Svetozar Putnik $^{2,3} \cdot$ Jovan Kosutic $^{1,2} \cdot$ Sanja Ninic $^{1} \cdot$ Sasa Popovic $^{1}$. \\ Ivana Cerovic ${ }^{1} \cdot$ Sergej Prijic $^{1,2}$
}

Received: 21 October 2020 / Accepted: 21 January 2021 / Published online: 11 February 2021

(C) Dr. K C Chaudhuri Foundation 2021

To the Editor: Arrhythmogenic right ventricular cardiomyopathy (ARVC) is an inherited progressive fibrofatty replacement of the right ventricular (RV) myocardium. Heart transplantation (HTx) is the final option for ARVC patients with the risk for cardiac death associated with either end-stage congestive heart failure or recurrent ventricular arrhythmias [1-4].

We present a boy with ARVC, initially manifested at the age of 10 with exercise-induced loss of consciousness caused by sustained ventricular tachycardia (sVT). Cardiac magnetic resonance demonstrated paradoxical movements of the RV anterior wall, increased normalized RV end-diastolic volume and decreased ejection fraction $\left(130 \mathrm{~mL} / \mathrm{m}^{2}\right.$ and $39 \%$, respectively) (Supplementary Fig. 1). The diagnosis was based on the two major criteria and confirmed by genetic analysis, which showed a novel mutation of the Plakophilin-2 gene (c.269272 Del; pN89fs110X). Upon diagnostic confirmation of the ARVC, implantable cardioverter defibrillator (ICD) was implanted. During the clinical course, progressive dysfunction of the left ventricle was noted (end-diastolic diameter $\mathrm{z}$ score of 3.9 and ejection fraction of $36 \%$ ). Cardiac ablation was performed three years after ICD implantation because of recurrent arrhythmia. The patient was treated with propafenone $(6 \mathrm{mg} / \mathrm{kg})$, amiodarone $(6 \mathrm{mg} / \mathrm{kg})$, and propranolol $(1.5 \mathrm{mg} / \mathrm{kg})$. However, arrhythmia remained to be untreatable and patient had an episode of 20 min lasting sVT during regular school activities, without appropriate termination regardless 8 subsequent direct current deliveries. Consequently, the boy

Sergej Prijic

sergej2804@gmail.com

1 Department of Cardiology, Mother and Child Health Care Institute of Serbia “Dr Vukan Cupic", R. Dakica St. 6-8, Belgrade 11070, Serbia

2 School of Medicine, University of Belgrade, Belgrade, Serbia

3 Department of Cardiac Surgery, Clinical Center of Serbia, Belgrade, Serbia underwent HTx with uneventful course at the age of 15 . The histopathological finding showed fibrofatty replacement of the myocardial muscle in the RV outflow tract and left ventricular subepicardial region.

Rate of the cardiac mortality and the need for HTx in ARVC patients are low (6\% and $4 \%$, respectively) [3, 4]. Independent predictor for HTx is young age at the time of the first symptoms [2]. Transplantation is rarely indicated in ARVC patients younger than 20 years [2,3]. To the best of our knowledge, this is the youngest patient with ARVC who underwent HTx due to untreatable arrhythmia.

Supplementary Information The online version contains supplementary material available at https://doi.org/10.1007/s12098-021-03679-8.

\section{Compliance with Ethical Standards}

Conflict of Interest None.

\section{References}

1. Basso C, Corrado D, Marcus FI, Nava A, Thiene G. Arrhythmogenic right ventricular cardiomyopathy. Lancet. 2009;373(9671):1289-300. https://doi.org/10.1016/S0140-6736(09)60256-7.

2. Gilljam T, Haugaa KH, Jensen HK, et al. Heart transplantation in arrhythmogenic right ventricular cardiomyopathy- experience from the Nordic ARVC registry. Int J Cardiol. 2018;250:201-6. https:// doi.org/10.1016/j.ijcard.2017.10.076.

3. Gilljam T, Bergh kan C. Right ventricular cardiomyopathy: timing of heart transplantation in Uhl's anomaly and arrythmogenic right ventricular cardiomyopathy. Eur J Heart Fail. 2009;11:106-9. https:// doi.org/10.1093/eurjhf/hfn014.

4. Corrado D, van Tintelen PJ, McKenna WJ, et al. International Experts. Arrhythmogenic right ventricular cardiomyopathy: evaluation of the current diagnostic criteria and differential diagnosis. Eur Heart J. 2019;0:1-16. https://doi.org/10.1093/eurheartj/ehz669.

Publisher's Note Springer Nature remains neutral with regard to jurisdictional claims in published maps and institutional affiliations. 